\title{
Rhabdomyolysis case based on hypothyroidism
}

\author{
Bilal Katipoglu, Ihsan Ates, Fatih Acehan, Ayșenur Meteris and Nisbet Yılmaz
}

Department of Internal Medicine, Ankara Numune Training and Research Hospital, Ankara, Turkey

\section{Summary}

Hypothyroidism is a wide clinical spectrum disorder and only a few cases in literature show this. Rhabdomyolysis and acute renal impairment can be seen concurrently in a hypothyroid state. We report a case of severe hypothyroidism with poor drug compliance leading to rhabdomyolysis and acute kidney injury.

\section{Learning points:}

- Hypothyroidism is a rare cause of acute kidney injury.

- In this case report, we studied a rare occurrence of acute renal impairment due to hypothyroidism with poor drug compliance, which induced rhabdomyolysis.

- Our report emphasized that thyroid status should be evaluated in patients with unexplained acute renal impairment or presenting with the symptoms of muscle involvement.

\section{Case presentation}

A 53-year-old male was admitted to a hospital with 15 days history of dyspnoea, weakness and oliguria, and muscle pain. His medical history included pulmonary thromboembolic, hypertension and cardiac arrhythmia. He had undergone total thyroidectomy for papillary thyroid cancer two years ago. His medication consisted of metoprolol, enoxaparin and L-thyroxine with no use in the past 4 weeks. Physical examination revealed dry and pale skin and slow speech. His pulse rate was 55 beats/minute and blood pressure was $130 / 90 \mathrm{~mm} \mathrm{Hg}$. Electrocardiography has shown bigemine ventricular extra systole. Laboratory investigations showed the following values: creatine phosphokinase, $1560 \mathrm{U} / \mathrm{L}$ (reference range, 52-336U/L); creatinine, $2.1 \mathrm{mg} / \mathrm{dL}$ $(0.2-1.0 \mathrm{mg} / \mathrm{dL}) ;$ potassium, $5.3 \mathrm{mEq} / \mathrm{L}(3.5-5.0 \mathrm{mEq} / \mathrm{L})$; thyroid-stimulating hormone (TSH) $43.2 \mu \mathrm{IU} / \mathrm{mL}(0.4-4.8$ $\mathrm{uIU} / \mathrm{mL}$ ), free thyroxine (fT4) $<0.3 \mathrm{ng} / \mathrm{dL}(1.71-2.8 \mathrm{ng} / \mathrm{dL}$ ) and free triiodothyronine (fT3) $0.48 \mathrm{pg} / \mathrm{mL}(1.57-4.71 \mathrm{pg} /$ $\mathrm{mL})$. Haematological tests showed haemoglobin $9.4 \mathrm{~g} / \mathrm{dL}$ (12-16), white cell count $9000 \mu \mathrm{L}$ and platelet counts were in normal range. His urine was bloody in appearance and urine analysis showed blood reaction with dipstick test, but no erythrocytes were found on microscopic examination. Fraction excretion of $\mathrm{Na}$ and urinary $\mathrm{Na}$ were high $(2.6 \%$ and $46 \mathrm{mEq} / \mathrm{L}$, respectively). Renal tract ultrasonography was normal. No signs suggested the presence of an associated infectious or systemic inflammatory disease. In addition, other causes resulting in rhabdomyolysis such as muscular trauma, drugs and toxins were excluded with history and laboratory investigations. His condition was diagnosed as acute kidney injury secondary to hypothyroidism-induced rhabdomyolysis. This case was also consulted with the department of cardiology physicians who started him on metoprolol $25 \mathrm{mg}$ before beginning thyroid replacement therapy. Cardiac status remained stable: L-thyroxine 25 microgram/day was prescribed, then 2 weeks later it was continued with L-thyroxine 50 microgram/day. His fluid deficiency was treated aggressively. His symptoms resolved over the following 3 weeks. 
Table 1 Main laboratory results on admission and during follow-up.

\begin{tabular}{lcc}
\hline Laboratory investigations & & 0 day \\
\cline { 1 - 1 } CK $(\mathrm{U} / \mathrm{L})$ & & 1560 \\
Creatinine $(\mathrm{mg} / \mathrm{dL})$ & 2.1 \\
LDH $(\mathrm{U} / \mathrm{L})$ & 437 \\
AST $(\mathrm{U} / \mathrm{L})$ & 312 \\
FT4 $(\mathrm{ng} / \mathrm{dL})$ & $<0.3$ \\
TSH $(\mu \mathrm{lU} / \mathrm{mL})$ & 43.2 \\
Thyroxine dose microgram/day & 25 \\
\hline
\end{tabular}

\begin{tabular}{c}
\hline 3 days \\
\hline 670 \\
1.7 \\
- \\
- \\
- \\
- \\
25 \\
\hline
\end{tabular}

\begin{tabular}{c}
\hline $\mathbf{7}$ days \\
\hline 300 \\
1.3 \\
230 \\
160 \\
- \\
- \\
25 \\
\hline
\end{tabular}

\begin{tabular}{c}
\hline 14 days \\
\hline 75 \\
0.8 \\
68 \\
42 \\
1.2 \\
20 \\
50 \\
\hline
\end{tabular}

CK, creatine kinase (30-135 U/L); AST, aspartate aminotransferase (9-52 U/L); LDH, lactate dehydrogenase (50-245 U/L); FT4, free thyroxine 4 (1.71-2.8ng/dL); $\mathrm{TSH}$, thyroid-stimulating hormone $(0.4-4.8 \mu \mathrm{IU} / \mathrm{mL})$.

\section{Investigation treatment follow up}

Main laboratory results on admission and during follow up has been showed in Table 1 .

\section{Discussion}

Hypothyroidism can be manifested with muscular symptoms such as myalgia, proximal muscle weakness and cramps. The exact cause of rhabdomyolysis in hypothyroidism has not as yet been fully clarified; the widely accepted hypothesis is that impaired glycogen lysis or impaired mitochondrial oxidative metabolism in hypothyroidism may be responsible for rhabdomyolysis $(1,2,3)$.

In our case, hypothyroidism was the cause of rhabdomyolysis because of lack of other etiologic agents resulting in rhabdomyolysis. In addition, clinical manifestations have occurred after stopping L-thyroxine. Moreover, the recovery of clinical symptoms and renal functions after thyroxine replacement therapy supported that and acute renal impairment due to rhabdomyolysis has been induced by hypothyroidism.

The pathophysiology of renal dysfunction in hypothyroidism is not understood thoroughly. Renal impairment with hypothyroidism is thought to be due to reduced cardiac output leading to reduced renal blood and decreased GFR. In addition, T3 showed direct effect on systemic vascular resistance, thus causing renal dysfunction. Furthermore, brain natriuretic peptide levels have correlation with free T3 and T4 levels (4). Also, it has been recently shown that $\mathrm{T} 4$ is known to regulate $\mathrm{Na}^{+} / \mathrm{Ca}^{2+}$ channels and $\mathrm{Na}^{+} / \mathrm{K}^{+}$-ATPase activity in the sarcoplasmic reticulum of nephrons (5). Another important mechanism of renal dysfunction in hypothyroidism is through muscle involvement. Whereas, like in our cases, acute renal impairment due to rhabdomyolysis induced by hypothyroid state is quite rare (6).
Prakash et al. observed the serum levels of thyroid hormones and CK in hypothyroid patients display inverse ratio. Moreover, serum $\mathrm{CK}$ levels can be an important marker for screening the hypothyroid patients (7). Also in our cases CK level measured higher than the normal limit.

Most of the previously reported cases of rhabdomyolysis associated with hypothyroidism analysis demonstrated that early aggressive fluid replacement with saline is an important factor in the recovery phase of AKI (8). For that reason, we treated fluid deficiency as soon as possible. Therefore, renal functions were fully recovered.

Hypothyroidism can adversely affect the haematological system and lead to the development of anaemia. We noted that the patient had reported having chronic anaemia. After treatment with levothyroxine, the patient's haemoglobin levels returned to normal when followed up 2 months after hospital discharge.

Although hypothyroidism can be accompanied with asymptomatic mild to moderate higher CK level, as far as we know, few previous cases of AKI due to rhabdomyolysis have been associated with hypothyroidism alone (1).

Declaration of interest

The authors declare that there is no conflict of interest that could be perceived as prejudicing the impartiality of the research reported.

\section{Funding}

This research did not receive any specific grant from any funding agency in the public, commercial or not-for-profit sector.

\section{Patient consent}

No consent form required as the patient was deceased a few months upon discharge.

Author contribution statement

All co-authors were involved in the patient's diagnosis and treatment process in our department. This case was also documented as a report. 


\section{References}

1 Altay M, Duranay M \& Ceri M 2005 Rhabdomyolysis due to hypothyroidism. Nephrology Dialysis Transplantation 20 847-848. (doi:10.1093/ndt/gfh745)

2 Barahona MJ, Mauri A, Sucunza N, Paredes R \& Wagner AM 2002 Hypothyroidism as a cause of rhabdomyolysis. Endocrine Journal 49 621-623. (doi:10.1507/endocrj.49.621)

3 Monzani F, Caraccio N, Manca L, Murri L \& Ferrannini E 1997 Clinical and biochemical features of muscle dysfunction in subclinical hypothyroidism. Journal of Clinical Endocrinology \& Metabolism 82 3315-3318. (doi:10.1210/jc.82.10.3315)

4 Schultz M, Faber J, Kistorp C, Jarlov A, Pedersen F, Wiinberg N \& Hildebrandt P 2004 N-Terminal-Pro-B-Type Natriuretic Peptide
(NT-Pro-BNP) in different thyroid function states. Clinical Endocrinology 60 54-59. (doi:10.1111/j.1365-2265.2004.01941.x)

5 Mcdonough A, Brown TA, Horowitz B, Mcdonough A, Brown TA \& Horowitz B 1988 Throid hormone coordinately regulates Na+-K+Atpase subunit mrna levels in kidney. American Journal of Physiology: Cell Physiology 254 323-329.

6 Cai Y \& Tang L 2013 Rare acute kidney injury secondary to hypothyroidism-induced rhabdomyolysis. Yonsei Medical Journal 54 172-176. (doi:10.3349/ymj.2013.54.1.172)

7 Prakash A, Lal KA \& Negi KS 2007 Serum creatine kinase activity in thyroid disorders. JK Science 9 25-26.

8 Huerta-Alardín AL, Varon J \& Marik PE 2005 Bench-to-bedside review: rhabdomyolysis-an overview for clinicians. Critical Care 92.

Received in final form 20 September 2016

Accepted 23 September 2016 